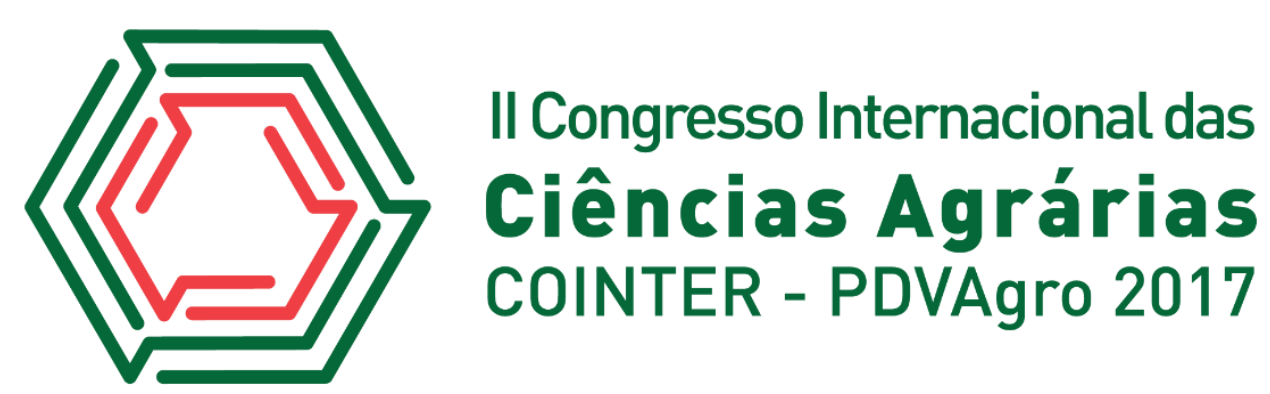

\title{
AGREGADOS E ESTOQUE DE CARBONO EM SOLO CULTIVADO COM PASTAGEM NO OESTE BAIANO
}

\author{
Apresentação: Pôster \\ Paulino Joaquim Soares Neto Sol ${ }^{1}$; Laise de Souza Silva ${ }^{2}$, \\ Vandayse Abades Rosa ${ }^{3}$; Heliab Bomfim Nunes ${ }^{4}$ Joaquim Pedro Soares Neto ${ }^{5}$
}

\section{Introdução}

Sabe-se que o carbono é um nutriente natural do solo, e garante os ciclos dos componentes físicos, químicos e biológicos, servindo de alimentos às plantas no decorrer de seu desenvolvimento vegetativo. E tem importante papel no solo, pois garante menor quantidade de insumos, maior conservação de água e menor compactação.

Atualmente, os modelos de superfície usados na agricultura têm objetivos além de simplesmente simular como a produtividade das culturas pode responder as mudanças climáticas e variações no $\mathrm{CO}_{2}$, embora esses temas ainda sejam foco de pesquisas (Kuchariket al., 2007). Em vez disso, as aplicações são mais diversas e ainda mais desafiantes. Muitos modelos estão sendo refinados para simular as mudanças no uso da terra. Culturas mais precoces, substituição de florestas por lavouras, irrigação, adubação inorgânica e manejo dos resíduos das culturas são alguns dos aspectos que estão sendo incorporados nos modelos de superfície da atual geração.

A reserva de carbono na matéria orgânica do solo é uma importante estratégia para atenuar a concentração de $\mathrm{CO}_{2}$ na atmosfera (RUFINO 2009). Portanto o monitoramento das alterações dos estoques de carbono no solo tem sido indicador dos efeitos do manejo e uso do solo (CONCEIÇÃO et al., 2008).

\footnotetext{
${ }^{1}$ Graduando em Engenharia Agronômica, Universidade do Estado da Bahia (UNEB) paulinoagro@ hotmail.com,

${ }^{2}$ Graduanda em Engenharia Agronômica, Universidade do Estado da Bahia (UNEB), laisinha_02@ @otmail.com

${ }^{3}$ Graduanda em Engenharia Agronômica, Universidade do Estado da Bahia (UNEB), deyseabades@ @otmail.com

${ }^{4}$ Mestre em microbiologia do solo, Universidade do Estado da Bahia (UNEB), heliabnunes@ hotmail.com

${ }^{5}$ Doutor em Geotecnia, Universidade do Estado da Bahia (UNEB), jpsneto@uneb.br
} 
Portanto objetivou-se com esse estudo, avaliar a influencia da pastagem nas propriedades físicas do solo, estoques de carbono no solo e $\mathrm{CO}_{2}$ equivalente, nos solos do Oeste da Bahia.

\section{Fundamentação Teórica}

As pastagens ocupam cerca de 170 milhões de hectares do território brasileiro e representam a base da exploração pecuária. No país existem aproximadamente $25 \%$ da área territorial ocupada com pastagens, sendo que $20 \%$ correspondem a pastagens degradadas de plantas do gênero Brachiaria. Estima-se que os pastos ocupem 9,18 milhões de hectares no estado de São Paulo, constituídas a maior parte por plantas do gênero Brachiaria, e que aproximadamente 50\% desse total já se encontram em algum estádio de degradação (TEIXEIRA, 2010). A contribuição da agricultura à emissão de $\mathrm{CO}_{2}$ é decorrente do preparo do solo com arado e grade que propicia a redução da matéria orgânica pelo rompimento dos agregados e aumento da oxidação do carbono orgânico em $\mathrm{CO}_{2}$.

Os resultados obtidos em pesquisas mostram que as pastagens bem manejadas apresentam aumento dos estoques de $\mathrm{C}$ nos solos em função do tempo de implantação das gramíneas. Valores na ordem de 0,4 a $0,6 \mathrm{~kg} \mathrm{C} \mathrm{m}^{2}$ ano ${ }^{-1}$ tem sido relatados para a camada 0 - $30 \mathrm{~cm}$ de profundidade do solo em pastagens bem manejadas (CERRI et al., 2006).

\section{Metodologia}

\section{Caracterização da Área em Estudo}

O estudo foi realizado na fazenda São João que fica situada no município de Barreiras na Região Oeste da Bahia. Foram selecionados talhões com plantio de pastagem, além da área de cerrado nativo.

\section{Clima}

De acordo a classificação de Koppen o clima predominante da região é do tipo Aw, ou seja, tropical sub úmido com período chuvoso de outubro a abril e período seco de maio a setembro.

\section{Amostragens}

Solo

Foram abertos perfis em quatro pontos em talhões com idades de três, e vinte anos, além da área de cerrado nativo nas profundidades de $0-0,10 ; 0,10-0,20 ; 0,20-0,30$ e 0,30 - 0,40 m nos 
quais foram coletadas amostras indeformadas com o auxilio de um trado e anel volumétrico para as análises de densidade e estabilidade de agregados. E amostras deformadas para analise do carbono orgânico total. As amostras foram devidamente identificadas e encaminhadas para o laboratório de Física dos Solos da Universidade do Estado da Bahia (UNEB), Campus IX.

\section{Carbono orgânico total}

O carbono orgânico total, foi determinado por oxidação a quente com dicromato de potássio em meio sulfúrico (Embrapa, 2011) e o estoque de carbono em cada uma das camadas amostradas foi estimado a partir da expressão:

Est $\mathrm{C}=\mathrm{COT}^{*} \mathrm{Ds}^{* \mathrm{e}}$

Onde: EstC é o estoque de carbono em $\mathrm{Mg} \mathrm{ha}^{-1}$; COT indica o teor de carbono orgânico em g/kg; Ds é a densidade do solo da camada estudada em $\mathrm{kg} \cdot \mathrm{dm}^{-3}$ e "e" a espessura da camada em centímetros (ALMEIDA,2014).

\section{Estabilidade de Agregados em água}

A estabilidade dos agregados foi determinada em amostras destorroadas cuidadosamente com as mãos quebrando os agregados maiores em seus pontos de fragilidade natural e posteriormente secas ao ar. Após esse processo, as amostras foram passadas num conjunto de peneiras, os agregados retidos na peneira de 8-10 $\mathrm{mm}$ foram utilizados para serem processados. Retirou-se 4 amostras de 50g por cada profundidade, em seguida essas amostras foram colocadas na parte superior de um jogo de peneiras de malhas $2,00 \mathrm{~mm} ; 1,00 \mathrm{~mm} ; 0,50 \mathrm{~mm} ; 0,25 \mathrm{~mm}$ e 0,106 $\mathrm{mm}$. Estas foram umedecidas com um atomizador e aguardado 10 minutos. Em seguida as amostras foram imersas no tanque do aparelho de Yoder para oscilação vertical por 15 minutos. Os agregados retidos em cada peneira foram transferidos para cápsulas de alumínio e levadas a estufa de circulação forçada por 24 horas a $105^{\circ} \mathrm{C}$ e na sequencia foi pesada cada fração (SALTON, 2012).

\section{Resultados e Discussões}

Observa-se na Tabela 1,que o maior teor de macroagregados foi da área de cerrado natural. Isso provavelmente ocorreu devido ao fato de estar presente uma maior diversidade de material vegetal na área, fazendo com que o solo seja protegido por esse material e consequentemente obtem uma maior estabilidade de agregados. A atividade do sistema radicular das gramíneas, associado à ausência de revolvimento do solo, contribui efetivamente para formação de macroagregados estáveis, conforme os dados apresentados por Pinheiro et al. (2004). Já em relação ao percentual 
de microagregados, o maior teor foi o da área de pastagem, assim como os macroagregados dessa mesma área teve o menor valor, comparado ao do sistema natural, isso deve estar relacionado ao fato da área nativa não ter preparo, fazendo com que não haja uma perturbação na mesma. Com isso, a matéria orgânica é mais presente, agindo como uma barreira física e a agregação seja estabilizada.

Tabela 1: Classes de agregados em áreas cultivadas com pastagem na região Oeste da Bahia, 2017.

\begin{tabular}{|c|c|c|}
\hline \multicolumn{2}{|c|}{ Classe de agregados } & \multirow[b]{2}{*}{ Microagregados } \\
\hline Áreas & Macroagregados & \\
\hline \multirow{4}{*}{$\begin{array}{c}\mathrm{CN} \\
\text { pastagem }\end{array}$} & -----(\%)------ & \\
\hline & 98,02 a & $1,98 b$ \\
\hline & 89,42 b & $6,61 a$ \\
\hline & $\mathrm{dms}=3,47$ & Dms $=2,45$ \\
\hline
\end{tabular}

Médias seguidas pela mesma letra não diferem estatisticamente entre si pelo teste de Tukey a 5\% de probabilidade de erro. $\mathrm{CN}=$ Cerrado nativo

Em relação ao estoque de carbono e $\mathrm{CO}_{2}$ equivalente, pode ser observado nas Tabelas 2 e 3, que na profundidade de 0 a $0,10 \mathrm{~m}$, os valores dessas variáveis foram inferiores na área de pastagem em relação à outra área estudada $(\mathrm{CN})$. Nas camadas mais subsuperficiais (20-30 e 30-40) apresentaram valores de estoque $\mathrm{C}$ e $\mathrm{CO}_{2}$ elevados na área do cerrado natural comparado à área de pastagem. isso deve ocorrer devido à diversidade de material vegetal na área nativa, que ao longo do tempo vai sendo decomposta e o carbono vai se acumulando nessas camadas. Com isso, tende a uma redução do acúmulo de matéria orgânica com o aumento da profundidade. Andrea et al. (2004), avaliando um Latossolo Vermelho Distrófico de textura média, localizado no sul de Goiás, obtiveram para uma pastagem de Brachiaria decumbes Stafp, de 15 anos, o estoque de C camada de 0-40 cm superior às demais camadas.

Tabela 2: Estoque de carbono total no solo em áreas cultivadas com pastagem na região Oeste da Bahia, 2017.

\begin{tabular}{ccccc}
\hline \multicolumn{5}{c}{ Estoque de C } \\
\hline Áreas & -Profundidade-(m) & $\mathbf{0 , 1 0 - 0 , 2 0}$ & $\mathbf{0 , 2 0 - 0 , 3 0}$ & $\mathbf{0 , 3 0 - 0 , 4 0}$ \\
\hline CN & $\mathbf{0 - 0 , 1 0}$ & $\mathbf{1 4 , 8 1 a A}$ & $\mathbf{1 0 , 9 a B C}$ & $\mathbf{9 , 3 8 a A}$ \\
pastagem & $\mathbf{1 3 , 5 7 a A B}$ & $\mathbf{9 , 2 5 a B}$ & $\mathbf{5 , 5 4 b C}$ & $\mathbf{4 , 1 0 b C}$ \\
\hline & $12,31 a A$ & & $\mathbf{C V}=15,70 \%$ \\
\hline
\end{tabular}

As letras minúsculas indicam as medias na coluna e nas linhas as letras maiúsculas. As médias seguidas pela mesma lesta não diferem estatisticamente entre si pelo teste de Tukeyà 5\% de probabilidade de erro. CN=Cerrado nativo. 
Tabela 3: Estoque de carbono total no solo em áreas cultivadas com pastagem na região Oeste da Bahia, 2017.

\begin{tabular}{ccccc}
\hline \multicolumn{5}{c}{$\mathrm{CO}_{2}$ equivalente } \\
\hline Áreas & -Profundidade-(m) & & & \\
& $\mathbf{0 - 0 , 1 0}$ & $\mathbf{0 , 1 0 - 0 , 2 0}$ & $\mathbf{0 , 2 0 - 0 , 3 0}$ & $\mathbf{0 , 3 0 - 0 , 4 0}$ \\
\hline CN & $\mathbf{4 9 , 8 0 a A B}$ & $\mathbf{5 4 , 3 4 a A}$ & $\mathbf{4 0 , 2 5 a B C}$ & $\mathbf{3 4 , 4 1 a C}$ \\
pastagem & $\mathbf{4 5 , 2 0 a A}$ & $\mathbf{3 3 , 9 6 b B}$ & $\mathbf{2 0 , 3 3 b C}$ & $\mathbf{1 5 , 0 5 b C}$ \\
\hline & & & & $\mathbf{C V}=15,70 \%$ \\
\hline
\end{tabular}

As letras minúsculas indicam as medias na coluna e nas linhas as letras maiúsculas. As médias seguidas pela mesma lesta não diferem estatisticamente entre si pelo teste de Tukeyà $5 \%$ de probabilidade de erro. $\mathrm{CN}=\mathrm{Cerrado}$ nativo.

\section{Conclusões}

O percentual de macroagregados foi superior na área de cerrado nativo.

Nas camadas subsuperficiais $(0,20-0,30 \mathrm{~m} ; 0,30-0,40 \mathrm{~m})$ apresentaram valores de estoque de $\mathrm{C}$ e $\mathrm{CO}_{2}$ equivalente, maiores no Cerrado e inferiores na área de pastagem.

\section{Referências}

ALMEIDA, A.S.A. et al.Biomass and Carbon stocks of Sofala Bay Mangrove Forests. Faculty of Agronomy and Forestry, 2014.

ANDREA, A. F. d' et al. Estoque de carbono e nitrogênio e formas de nitrogênio mineral em um solo submetido a diferentes sistemas de manejo. Pesquisa Agropecuária Brasileira Brasília, v. 39, n. 2, p. 179-86, fev. 2004.

CERRI C.E.P.M. et al. Simulatingsoilorganiccarbonchanges in elevenland use changechronosequencesfromtheBrazilianAmazonwithRothCandCenturymodels. Agr. Ecosyst. Environ.,Amsterdan, 122: 2006. 46-57

EMPRESA BRASILEIRA DE PESQUISA AGROPECUÁRIA - EMBRAPA. Manual de métodos de análise de solo. 2. ed. Revisada. Rio de Janeiro: Embrapa Solos, 2011 .

KUCHARIK, C.J., FOLEY, J.A., DELIRE, C., FISHER, V.A., COE, M.T., GOWER, S.T., LENTERS, J.D., YOUNGMOLLING, C., NORMAN, J. M., \& RAMANKUTTY, N. Testing the performance of a dynamic global ecosystem model: water balance, carbon balance end vegetation structure. Global Biogeochemical Cycles, v.14, p. 795-825, 2000.

PINHEIRO, E.F.M.; PEREIRA, M.G. \& ANJOS, L.H.C.Aggregate distribution and soil organic matter underdifferent tillage systems for vegetable crops in a Red Latosol from Brazil.SoilTill. Res., 77:79-84, 2004.

TEIXEIRA, E. M. L. C.Estoque de carbono em pastagens com diferentes sistemas de uso e manejo. Dissertação (Mestrado) - Instituto de Zootecnia. Nova Odessa - SP, 2010. 88p 